\title{
Flight Test Results for Uniquely Tailored Propulsion- Airframe Aeroacoustic Chevrons: Community Noise
}

\author{
Eric Nesbitt ${ }^{*}$; Vinod Mengle ${ }^{\dagger}$ and Michael Czech ${ }^{\ddagger}$ \\ The Boeing Company, Seattle, WA, 98124-2207 \\ Bryan Callendar ${ }^{\S}$ \\ GE Transportation, Cincinnati OH 45215 \\ And \\ Russ Thomas** $^{* *}$ \\ NASA Langley Research Center, Hampton, VA 23681-2199
}

\begin{abstract}
The flow/acoustic environment around the jet exhaust of an engine when installed on an airplane, say, under the wing, is highly asymmetric due to the pylon, the wing and the high-lift devices. Recent scale model tests have shown that such Propulsion Airframe Aeroacoustic (PAA) interactions and the jet mixing noise can be reduced more than with conventional azimuthally uniform chevrons by uniquely tailoring the chevrons to produce enhanced mixing near the pylon. This paper describes the community noise results from a flight test on a large twin-engine airplane using this concept of azimuthally varying chevrons for engines installed under the wing. Results for two different nozzle configurations are described: azimuthally varying "PAA T-fan" chevrons on the fan nozzle with a baseline no-chevron core nozzle and a second with PAA T-fan chevrons with conventional azimuthally uniform chevrons on the core nozzle. We analyze these test results in comparison to the baseline no-chevron nozzle on both spectral and integrated power level bases. The study focuses on the peak jet noise reduction and the effects at high frequencies for typical take-off power settings. The noise reduction and the absolute noise levels are then compared to model scale results. The flight test results verify that the PAA T-fan nozzles in combination with standard core chevron nozzles can, indeed, give a reasonable amount of noise reduction at low frequencies without high-frequency lift during take-off conditions and hardly any impact on the cruise thrust coefficient.
\end{abstract}

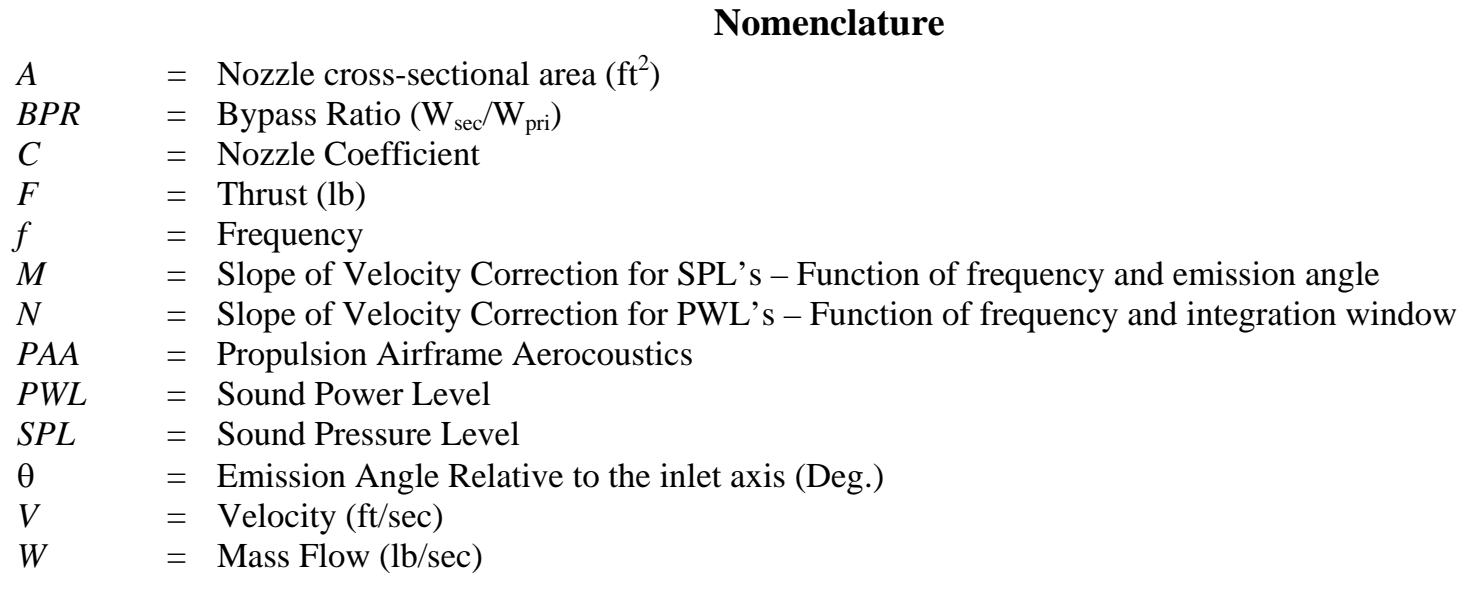

\footnotetext{
* Boeing Associate Technical Fellow, Noise Product Development, PO Box 3707 M/S OR-MM, AIAA Member.

† Scientist/Engineer, Acoustics \& Fluid Mechanics Dept., PO Box 3707, MC:67-ML, AIAA Senior Member.

‡ Scientist/Engineer, Acoustics \& Fluid Mechanics Dept., PO Box 3707, MC:67-ML, AIAA Member.

$\S$ Lead Engineer, Acoustics and Installation Aerodynamics, 1 Neuman Way, MS W26, AIAA Member.

** Senior Research Engineer, Aeroacoustics Branch, MS 166, and AIAA Senior Member.
} 


\section{Introduction}

$\mathrm{B}$ oeing, GE, Goodrich, NASA and ANA partnered to form the Quiet Technology Demonstrator 2 (QTD2) flight test project. The Boeing led project had many objectives and each partner brought various capabilities and interests to contribute to the overall objectives of the project. Herkes ${ }^{1}$ et al describes the background and overview of the QTD2 project. In brief, the QTD2 flight test project developed and demonstrated a variety of advanced acoustic measurement methods and noise reduction technology to produce new understanding of aircraft acoustics physics, to validate prediction methods and to validate and mature technology to flight test readiness. A variety of noise reduction technology was a part of QTD2 and included an acoustically smooth inlet, fan and core nozzles with unique chevrons, and modified landing gear concepts.

This paper describes the QTD2 flight test results focusing on two of the noise reduction concepts. The objective of the first concept was to design a unique chevron nozzle which accounts favorably for the effects created when an exhaust nozzle is integrated with a pylon (or strut) and the wing. These strut and wing effects are part of the overall effects created by the integration of propulsion and airframe and are described, in general, as Propulsion Airframe Aeroacoustic (PAA) effects. The flight test community noise results are analyzed for this uniquely tailored Propulsion Airframe Aeroacoustics fan chevron nozzle design. The results are considered with and without the second noise reduction concept, a state-of-the-art core chevron nozzle.

Chevron nozzles represent one of the most effective and feasible jet noise reduction technologies for application to modern high bypass ratio turbofan engines. These nozzles feature uniform triangular serrations in the nozzle trailing edge which immerse slightly into the inner stream so as to induce an array of streamwise vorticity into the shear layer downstream of the chevrons. This vorticity promotes increased mixing between the two streams surrounding the chevrons and leads to reduced jet plume length. This in turn leads to reduced centerline velocity and a decrease in low frequency jet noise. The fact that chevron nozzles are capable of reducing low frequency engine exhaust noise while imposing minimal impact on engine performance and weight make them a very attractive technology for commercial application. As a result of this, the past decade has seen a great deal of effort focused on developing this technology. For example, the pioneering efforts in developing chevrons for separate flow nozzles by Janardan et $\mathrm{al}^{2}$ through model scale experiments at NASA Glenn; later experiments by Martens ${ }^{3}$ including a strut and azimuthal effects; and flight test demonstration of nozzles with chevrons by Nesbitt ${ }^{4}$ et al. As a result of these and other significant in-house efforts at GE and Boeing, first generation chevron designs, which are typically azimuthally uniform, are now operating in revenue service on commercial engines.

One recent area of chevron research has focused on an improved understanding of the significance of chevron geometry and its effect on the frequency spectrum. Several research efforts have documented that the chevron spectral effects can be directly correlated to the amount that the chevrons are immersed in the flow. Specifically, it has been shown that greater chevron immersion leads to increased low frequency noise reduction. However, increased immersion also leads to increased high frequency noise as turbulence levels are increased near the nozzle exit. As a result of this, chevron designs developed to date have balanced this trade between low and high frequency noise to maximize aircraft system noise reduction. One of the goals of the current technology demonstration program was to leverage what has been learned in regard to chevron geometry to increase or maintain the low frequency noise benefits, while reducing or eliminating the high frequency increases.

An additional area of recent research has been to understand the PAA installation effects of chevron nozzles. PAA effects that are relevant include how the chevron nozzle might interact with or be impacted by the presence or integration with the strut, wing, and flaps. In particular, the effect of the strut on the development of the jet flow field and the resulting noise effects have been observed and studied at model scale by many recent studies $^{3,5-8}$. Elkoby ${ }^{9}$ has reviewed the PAA effects and analyzed the results between one recent static engine and flight test to quantify,

\begin{tabular}{|c|c|c|c|}
\hline $\begin{array}{c}\text { Config } \\
\text { No. }\end{array}$ & Inlet & $\begin{array}{l}\text { Ex- } \\
\text { haust }\end{array}$ & Description \\
\hline 1 & 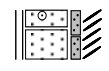 & $\sqrt{5}$ & Baseline \\
\hline 2 & : & $\beta$ & PAA Chevron + Core Chevron \\
\hline 4 & - & $\Leftrightarrow$ & PAA Chevron + Baseline Core \\
\hline 8 & 沄 & $\sqrt{5}$ & Baseline Nozzles \\
\hline
\end{tabular}

Table 1. PAA Nozzle Flight Test Configurations

with the available data and methods, PAA effects for that full-scale configuration including an interaction of the jet and wing and flap that was observed in the forward arc at lower frequencies.

With the background of these studies, the opportunity developed to take the highly successful chevron noise reduction approach and incorporate PAA principles to improve the overall noise reduction by accounting for the 
non-symmetric flow interactions that occur between the exhaust system, the engine strut, and the wing flow. This leads to a sourceobserver acoustic asymmetry; so, for example, if the observer is on the ground, as in take-off conditions, then the noise can, perhaps, be radiated away from the ground observer by varying the mixing around the nozzle periphery in a certain manner. Mengle et $\mathrm{al}^{10-12}$ has taken advantage of this fact and pioneered the concept of azimuthally varying chevrons (AVC) and made systematic scale-model tests to validate the idea that a chevron nozzle can be designed with a unique azimuthal variation of the chevrons that will produce enhanced noise reduction in the installed configuration relative to state-of-the-art azimuthally uniform chevrons. Mengle et $\mathrm{al}^{10-12}$ reports that one fan AVC design in particular, the so-called T-fan chevrons, with larger and more immersed chevrons close to the strut and smaller and less immersed chevrons away from the strut, was the most successful in terms of low frequency reduction without any high frequency lift. As a result, it was selected for flight test validation in the QTD2 program. In another paper, Massey et $\mathrm{al}^{13}$ presents a computational investigation using flow and noise predictions to propose an understanding of the connection between this unique T-fan chevron design and the resulting flow development and noise results, again relative to a uniform chevron design.

This paper focuses on the flight tests results of this T-fan chevron nozzle with and without a conventional core chevron nozzle to determine the community noise results at take-off conditions. A companion paper ${ }^{14}$ focuses on the acoustics results of these AVC nozzles for shock-cell noise reduction at cruise conditions important for interior cabin noise. In the next two sections we describe flight test configurations and the data analysis method, then we present the flight test results and conclude its applicability to high bypass ratio engines for more stringent noise restrictions.

\section{Flight Test Configurations}

Three nozzle configurations are relevant to this study: (i) the PAA T-fan chevron nozzle with the core chevron nozzle, (ii) the PAA Tfan chevron nozzle with the baseline core nozzle, and (iii) the baseline fan and core nozzle combination. The development of the flight test configuration matrix, of course, included many constraints related to priority

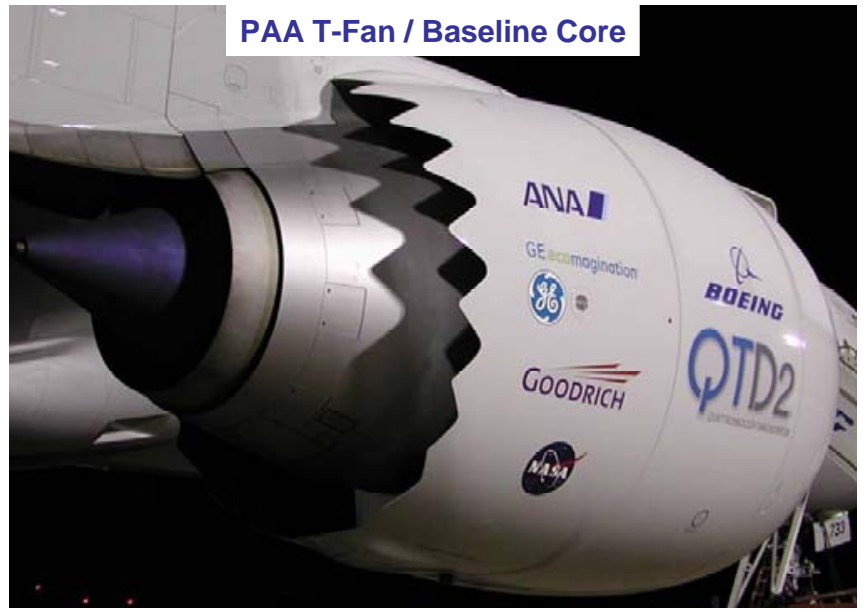

Figure 1. PAA T-Fan Nozzle Installed on the QTD2 airplane

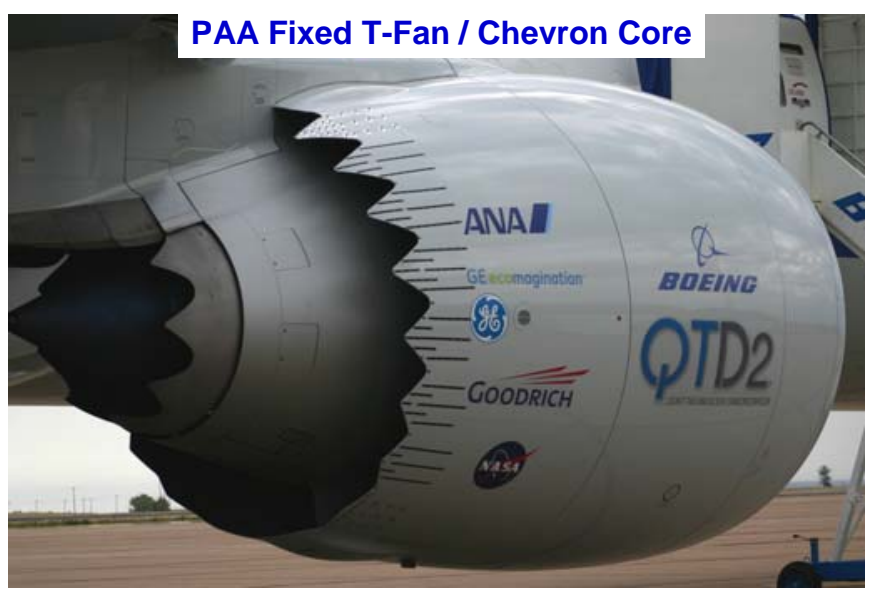

Figure 2. PAA T-Fan Nozzle/ Core Chevron Installed on QTD2 Airplane

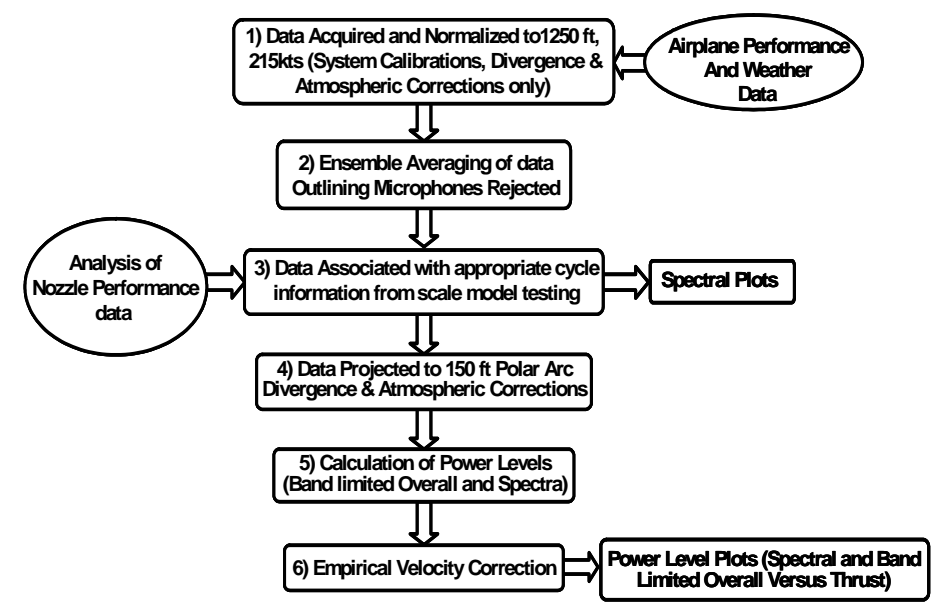

Figure 3. Flow Chart of Analysis method 
and schedule. The result was four flight tests that provided data on these three nozzles. Table 1 lists the four configurations and the important implications for the analysis that follows. The PAA T-fan chevron nozzle was tested with and without the core chevron nozzle in configurations 2 and 4 providing for the determination of the possible interaction effect of the fan and core chevrons. Both of these configurations included an Acoustically Smooth Inlet (ASI) that removed liner splices, moved the acoustic liner closer to the fan rotor, and added a lip liner $^{15}$. The baseline nozzles were tested on both Configs. 1 and 8 but the inlet was different: Config. 1 had the production inlet and Config. 8 had the ASI except for the lip liner. As the nozzle combinations are compared and studied later, we should keep in mind that these inlet features, therefore, can provide some possible variation in addition to normal flight test-to-test variation. Figure 1 shows the PAA T-fan nozzle with it's unique azimuthally varying design as it was installed on the airplane (Config. 4), and Figure 2 shows it in combination with the core chevrons (Config. 2).

Other chevron nozzle design issues are important to note. In addition to scale and some thicknesses that were intentionally changed, the PAA T-fan chevron nozzle flown on Configurations 2 and 4 had a key design change from the model scale design reported in Mengle et $\mathrm{al}^{10-12}$. The original model scale $\mathrm{T}$-fan nozzle, on subsequent performance testing, was found to have lower nozzle discharge coefficients than desired at low nozzle pressure ratios. This potentially affects fan operability, and the flight-ready design of the PAA T-fan chevron fan nozzle was redesigned to improve this aspect. However, that also led to a small reduction in noise benefit as compared to the original T-fan chevrons when tested at model scale in Boeing's Low Speed Aeroacoustics Facility (LSAF).

The core chevron nozzle, on the other hand, is a state-of-the-art azimuthally uniform design intended to minimize the potential high frequency increase while maximizing the low frequency reduction for the high bypass ratio engine cycle. This core chevron design was also slightly different and more optimized than the one reported in Mengle et $\mathrm{al}^{10-12}$ and was also tested at model scale with and without the PAA T-fan chevron nozzle and in the ASE FluiDyne facility for performance.

\section{Analysis method}

The following section outlines the analysis method for reducing the data from LSAF and also the QTD2 flight test. Figure 3 show the analysis method for the flight test data.

\section{A. Ensemble averaging method}

All data processing was accomplished using Boeing's Flight Test Acoustic Data Processing System ${ }^{1}$. Community noise data was acquired using two different microphone arrays. Flyover data was acquired using an ensemble array of eight Brüel and Kjær microphones mounted in a Boeing built "Flush-Dish" (ground-plane microphone ${ }^{1}$ ) installation. Most of the results presented in the paper were acquired by this array. Six additional ground plane microphones were mounted on a $1475 \mathrm{ft}$ sideline array. Selected results from this array will be presented in addition to data from the flyover array. The terrain, in the vicinity of the microphones, complies with the requirements specified in FAR 36 and ICAO Annex 16.

\section{B. Performance data normalization}

All comparisons presented in this paper will be made at equivalent thrust. This section will outline the testing and analysis procedures that allow this to be accomplished. Introduction of the chevron nozzles changes the nozzle thrust and discharge coefficients relative to the baseline nozzle designs. As a result of this, the chevron configurations will produce slightly different thrust levels for a given corrected fan speed. In order for meaningful comparisons to be made, these changes must be accounted for in the data processing. A high standard, model-scale performance test conducted at ASE FluiDyne for each nozzle configuration, gave the nozzle discharge and velocity coefficients. These coefficients were then included in the thermodynamic cycle model of the engine to allow an accurate relationship between thrust and

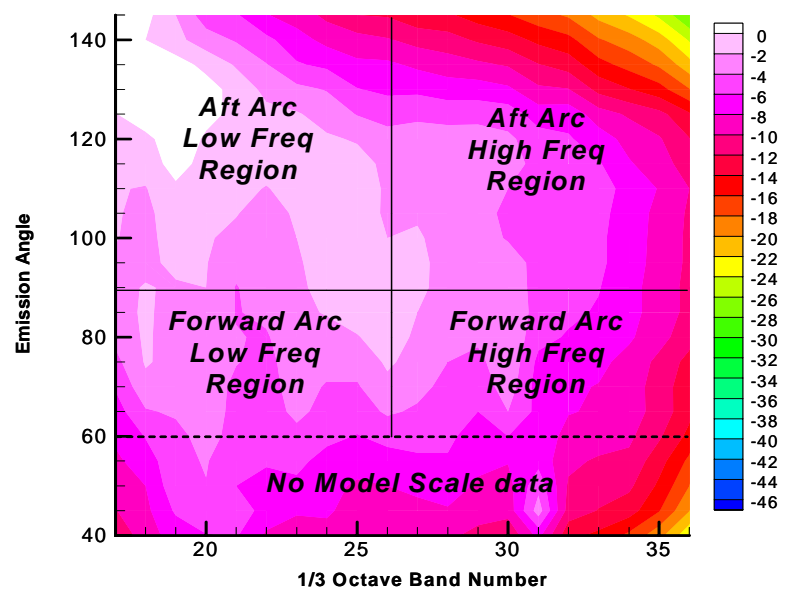

Figure 4. Integration Regions 
corrected fan speed to be determined for each nozzle configuration. The community noise data was acquired by setting the engine corrected fan speed to the prescribed test condition. Therefore, knowing this relationship for each test configuration allows the data to be associated with equivalent thrust levels so meaningful comparisons can be made. The nozzle discharge and velocity coefficients will be presented along with the noise data in the results section of this paper.

\section{Method for calculation of power levels}

There is significant variation in flight test data, especially in the high frequencies and from angle to angle. Flight test data scatter is caused by numerous factors, including but not limited to: non-homogenous atmospheric effects, effects due to terrain, and effects caused by how the airplane flew during the test condition. These effects can be significant (over $2 \mathrm{~dB}$ spectrally from one angle to the next) and can make it difficult, if not impossible, to measure relatively small noise changes due to chevrons. To help in this respect the analysis method first devised for QTD1 and reported by Nesbitt et $\mathrm{al}^{4}$ is employed. This method shown in flow chart form in Figure 3 involves the calculation of power levels. Since a power level is defined over a surface this method first projects the data to a 150 foot polar arc from the center of the core nozzle exit plane and then calculates the power levels assuming a uniform field over the spherical surface. This allows for spectral comparisons to be made, which are an integration over the angle, thereby significantly reducing much of the angle to angle scatter. Figure 4 shows the spectral-directivity regions over which the integration is performed $\left(1 / 3^{\text {rd }}\right.$ octave band no. $=10 \log \left(1 / 3^{\text {rd }}\right.$ octave band frequency)). First, spectral power levels are calculated over the forward and aft arc, then band limited overall power levels are calculated using two frequency domains. The band limited power levels are then used to look at the different regions as a function of thrust. The low frequency domain includes full scale bands 17 through 26 and the high frequency domain includes bands 27-36. The low frequency domain is chosen specifically to look at the effects on the jet noise without significant effects from other sources (upper band no. 26, representing $400 \mathrm{hz}$., being selected arbitrarily). Bands above 36 are ignored in this study since there is no model scale data to compare to, and since in the full scale flight test bands above 36 are mostly created by a band shaping process due to being at or below the ambient noise floor for most flyovers. This means the bands from flight testing at higher than approximately band 36 are not data in the true sense. Also since our model scale data does not extent forward of approximately 60 degrees of emission angle the
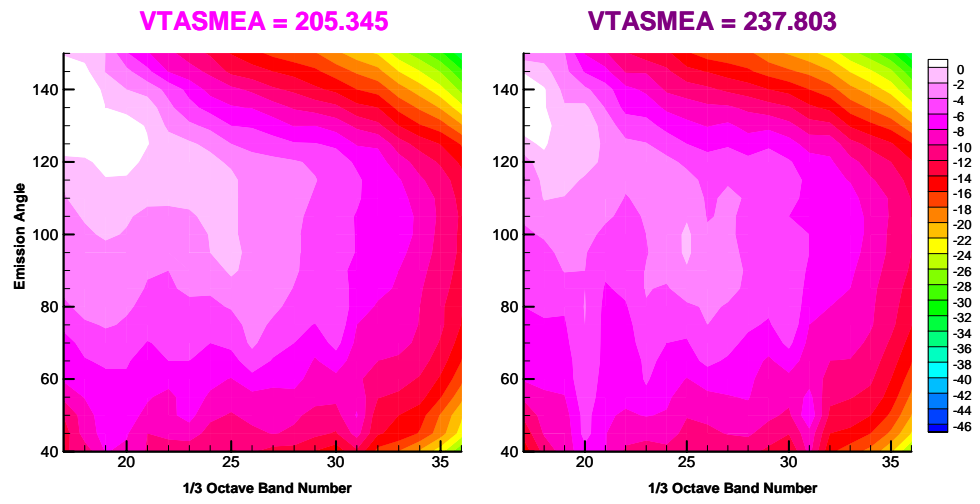

Figure 5. Effect of aircraft speed

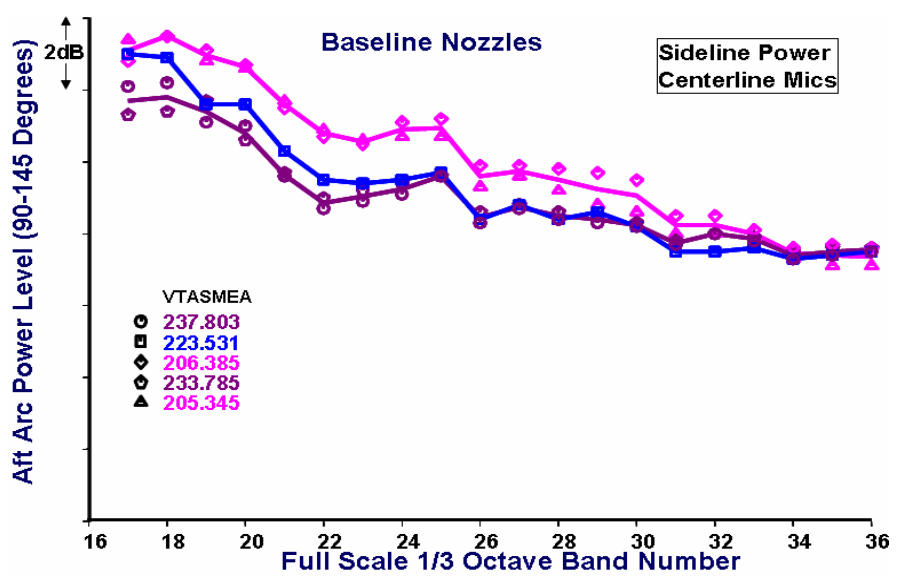

Figure 6. Effect of aircraft speed

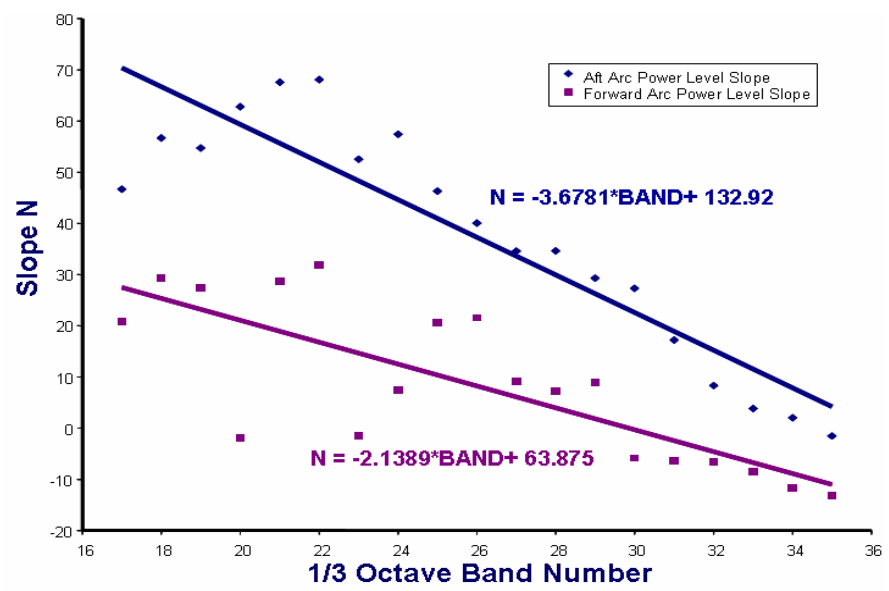

Figurg 7. Slope derivation for Velocity Correction

American Institute of Aeronautics and Astronautics 
integration in the forward arc is cut off at that point. This also helps reduce the contamination due to the inlet acoustic lining being different in the comparisons to be made. It should be stated that there is no other attempt made to separate the other noise sources for this comparison - this is of particular importance when looking at the results, particularly at lower powers and in the high frequency regions.

\section{Velocity corrections}

Jet noise levels are quite sensitive to changes in aircraft flight velocity. Unfortunately, the true airspeed of the aircraft cannot be controlled with the required accuracy as it is influenced by wind speed, thermal activity, and other uncontrollable atmospheric conditions. Therefore, it is necessary to develop corrections that will allow the acquired noise spectra to be corrected to a standard reference airspeed. In order to develop such a correction, and also to better understand the effects of true airspeed, a series of test conditions were flown where the aircraft flight velocity was intentionally varied over a range of airspeeds.

Figure 5 shows an example of the SPL contour plots in the frequency-angle plane with two different airspeeds (VTASMEA) for the same configuration. The results shown in Figure 5, and any time the data is displayed in this manner in this paper, are plotted with a given color representing the same absolute SPL value in both the plots. However, only the relative SPL scale is shown with the maximum noise level arbitrarily set to zero.

Figure 6 shows an example of the variation in aft arc power level spectra for all the conditions flown at different airspeeds.

As demonstrated by Nesbitt et $\mathrm{al}^{4}$ it is possible to derive an empirical correction to jet noise due to free stream speed differences. Here, instead of correcting model scale jet rig data the correction is derived from the full scale flight test data. The correction at any angle can therefore be assumed to be:

$$
\Delta S P L=M(f, \theta) \log \left[\frac{V_{\text {mix }}-V_{x}}{V_{\text {mix }}-V_{\text {ref }}}\right]
$$

where: $\mathrm{f}$ is frequency, $\theta$ is angle, $V_{\text {mix }}$ is the massflow rate averaged mixed jet velocity; $\mathrm{V}_{\mathrm{x}}$ is the true airspeed at any given condition and $V_{\text {ref }}$ is 371.58 $\mathrm{ft} / \mathrm{s}$ (or 220 knots). Since the power level is defined over a series of angles the correction becomes some other function of frequency, $\mathrm{f}$, only:

$$
\Delta P W L=N(f) \log \left[\frac{V_{\text {mix }}-V_{x}}{V_{\text {mix }}-V_{\text {ref }}}\right]
$$

where the slope $N(f)$ is derived as shown in Figure 7 and is a function whether the power level is in the forward or aft arc.

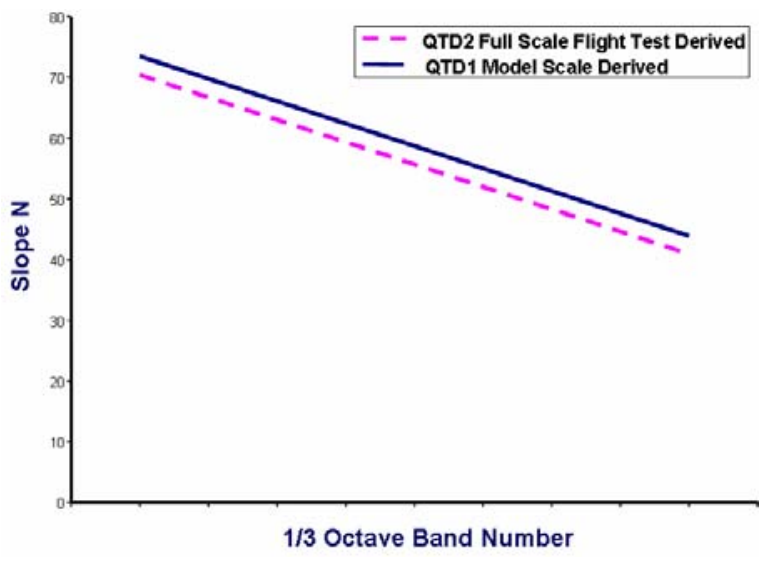

Figure 8. Velocity Slope Comparison

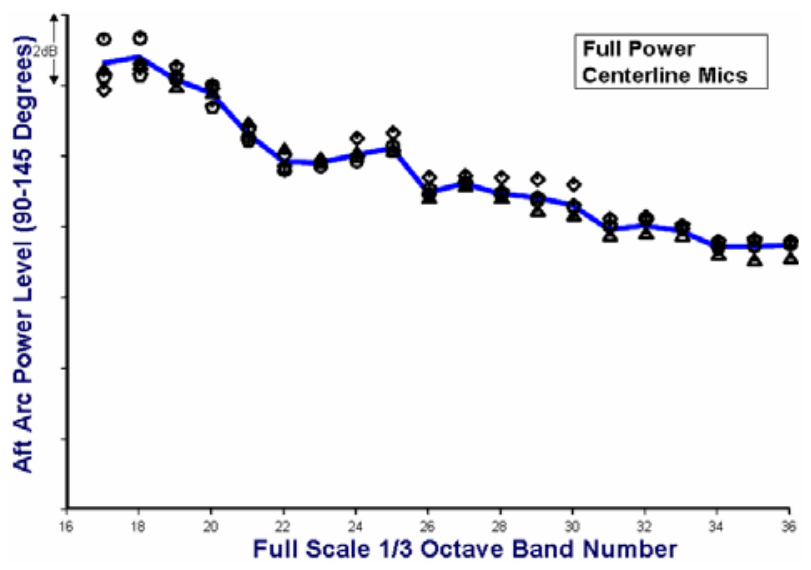

Figure 9. Velocity Correction Data Collapse

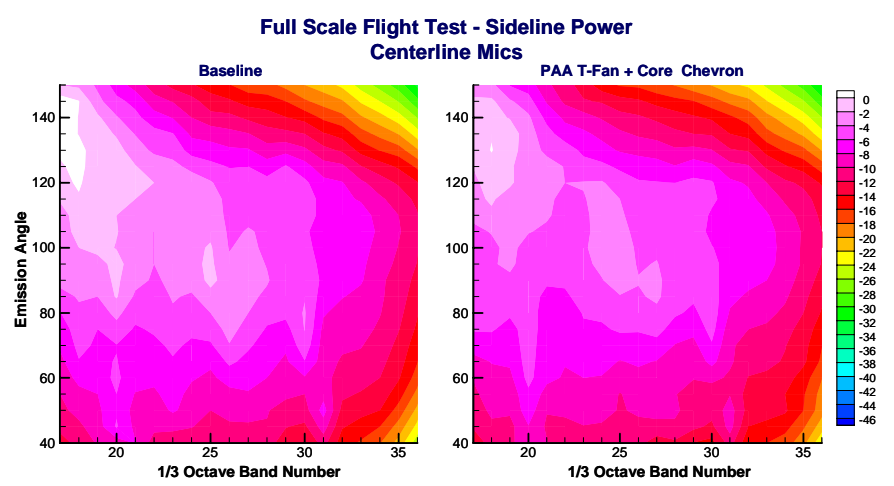

Figure 10. Baseline Versus PAA T-Fan + Core Chevron Max Power

This derived correction is then compared to the model-scale correction for the aft arc power level derived during QTD1 and presented by Nesbitt, et al ${ }^{4}$ in Figure 8. 
Due the differences in nozzle diameters and engine cycles there is some uncertainty in the conversion from Strouhal number (used by Nesbitt, et al ${ }^{4}$ ) to full scale $1 / 3$ octave band to make the comparison; however, it is remarkable that the curves have the same slope and are close to the same level. This further validates the approach for correction of the power levels to a common airplane speed.

This correction is applied to the data shown in Figure 6 and the resulting collapse is shown in Figure 9. As shown, the velocity correction collapses the data significantly so that valid comparisons can now be made.

\section{E. Model scale to full scale extrapolation}

It is desired to compare the flight test results to the model scale results obtained during the chevron development phase of the program. The details of this model scale development program were reported by Mengle et al. ${ }^{10-12}$ The projection of the model scale data to full scale is accomplished using the method described by Nesbitt $\mathrm{et}^{\mathrm{a}}{ }^{4}$, with the exception that the jet is modeled as a point source located at the core nozzle exit plane. Once the model scale data is projected to full scale, the data is processed as described in steps $4-6$ in Figure 3. The point source assumption has the known effect of shifting the peak jet noise to aft angles relative to what would be measured in a full scale aircraft flyover (due to the model size and the sound propagation distance).

As noted earlier the PAA T-Fan chevron design to be flight-tested was changed slightly to accommodate engine operational constraints and therefore is a specific design for the flight test and was not tested as part of the results presented by Mengle et al. ${ }^{10-12}$ This new design was tested later at model scale as an isolated (including pylon) nozzle in the jet rig at Boeing's Low Speed Aeroacoustic Facility and the results are presented here.

\section{Results}

The results are first shown for the flight test and then compared to the model scale results. The acoustic data is compared in three different ways: SPL in the band number-emission angle plane; power level comparisons; and band limited overall power levels as a function of thrust.

\section{A. Spectral comparisons}

For the spectral comparisons the conditions to compare were carefully chosen to be at equal thrust and airspeed. This was due to the infeasibility of not correcting for speed or plot versus corrected thrust for this type of comparison. The spectral comparisons are presented as color contour maps where the $\mathrm{x}$ axis is the full scale band number, and the $y$ axis is the emission angle relative to the inlet axis. Therefore the airplane can be considered to be flying from the bottom to the top of the contour maps for a ground observer. This section shows
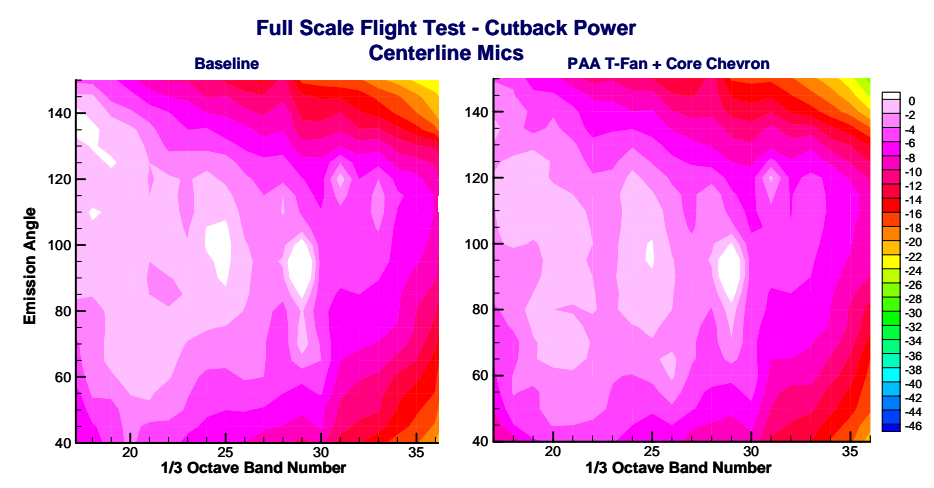

Figure 11. Baseline Versus PAA T-Fan + Core Chevron Cutback Power

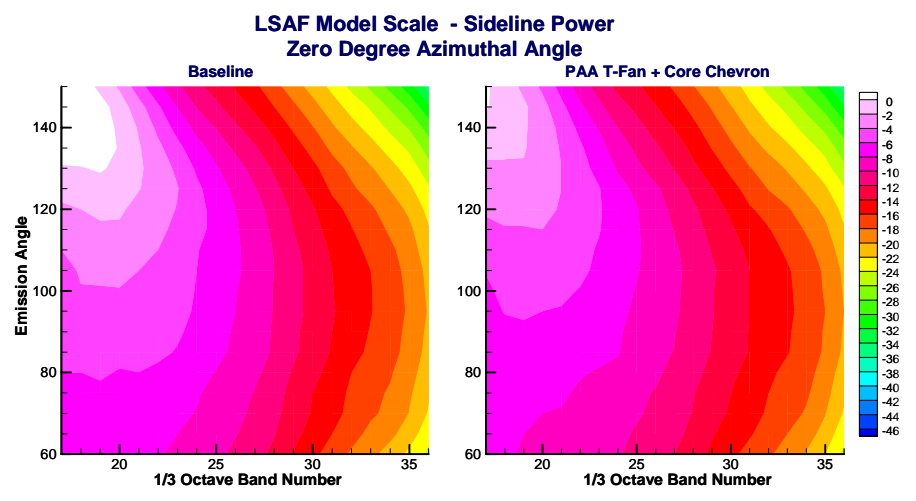

Figure 12. Model Scale Spectral Comparison - Max Power

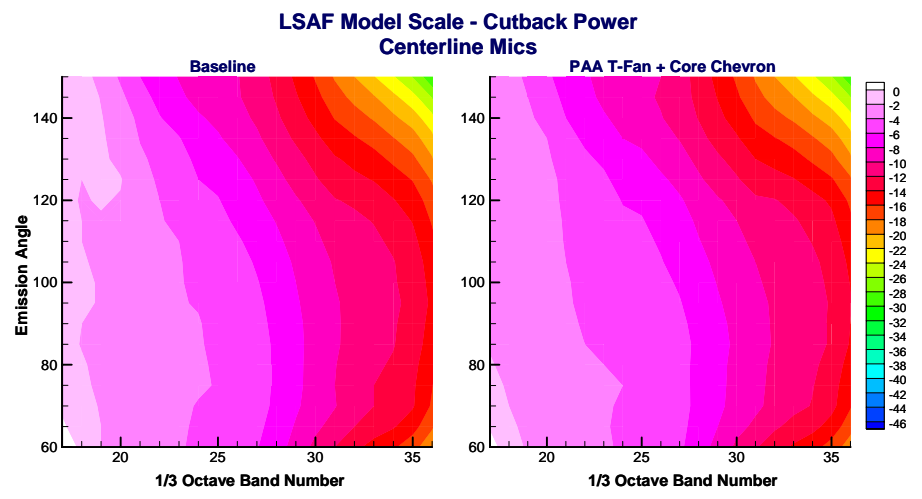

Figure 13. Model Scale Spectral Comparison - Cutback Power 
spectral comparisons with the baseline configuration of the entire sound field for the two configurations tested.

Figures 10 \& 11 show a side-by-side comparison of the PAA T-Fan + core chevron nozzle configuration with the baseline nozzle for the centerline microphones. Figure 10 shows the comparison for a typical full power takeoff power setting and Figure 11 shows the comparison at the cutback power setting. Although there are significant other (fan) noise sources, the jet noise is still known to dominate the aft arc low frequencies. As shown, there is a significant reduction (up to $\sim 2 \mathrm{~dB}$ ) in the low frequencies aft arc at both power settings. It should also be noted that there does not appear to be any significant high frequency increase in the forward arc although it should be remembered here that there is a difference in the inlet acoustic lining configuration which could somewhat offset any increase. This issue will be explored in more detail when the power levels are compared in section IV-B.

Figures 12 and 13 show the corresponding model-scale results for the PAA T-Fan and primary chevron nozzle set for full power and cutback. When examining Figure 13 it should be understood that at this relatively low cutback power the wind tunnel noise floor contaminates some of the forward arc data and any conclusions from this data at cutback power are uncertain.

There are three significant things to note when comparing Figures 12 and 13 to Figures 10 and 11. First, the peak jet noise is shifted aft relative to the full scale data (approx. $140^{\circ}$ vs. $130^{\circ}$ ). As previously described, this is due to the point source assumption in the model-scale data, whereas, the actual low frequency source may be several diameters downstream. Second, the model scale data seems to drop off in frequency significantly faster than the full scale data particularly in the aft arc region from about 90 to 120 degrees. This part of the noise contour map has been shown in Figure 6 to be dominated by jet noise and although there may be some effect here due to the point source assumption, there is no full explanation as to why this is the case. Third, the noise reduction is significant and although similar to the full scale results it does appear to be somewhat greater. Also, it may be due to the fact that data in figs. 11 and 12 is from an isolated nozzle test, not installed - so the effects of installation are not included. As described earlier, this is a single comparison where both the speed and thrust were comparable; the power level comparisons need to be examined before any firm conclusions can be made.

Figures $14 \& 15$ show the results of the PAA T-Fan + core chevron nozzle set for the sideline microphones. There are few items to notice about these sideline microphone comparisons. First, measurements at sideline are inherently more difficult and have a higher decree of scatter due to longer propagation paths and shallower elevation angles. Also due to

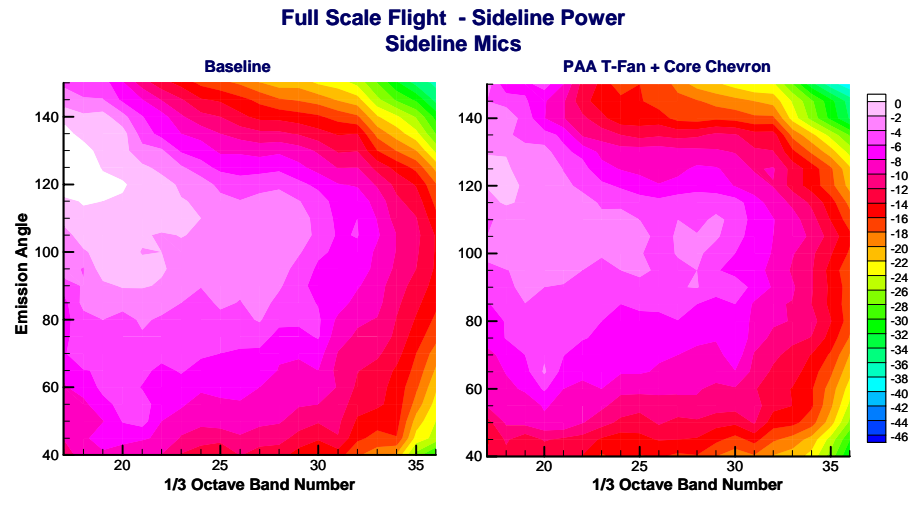

Figure 14. PAA T-Fan at Sideline - Max Power Full Scale Flight - Cutback Power

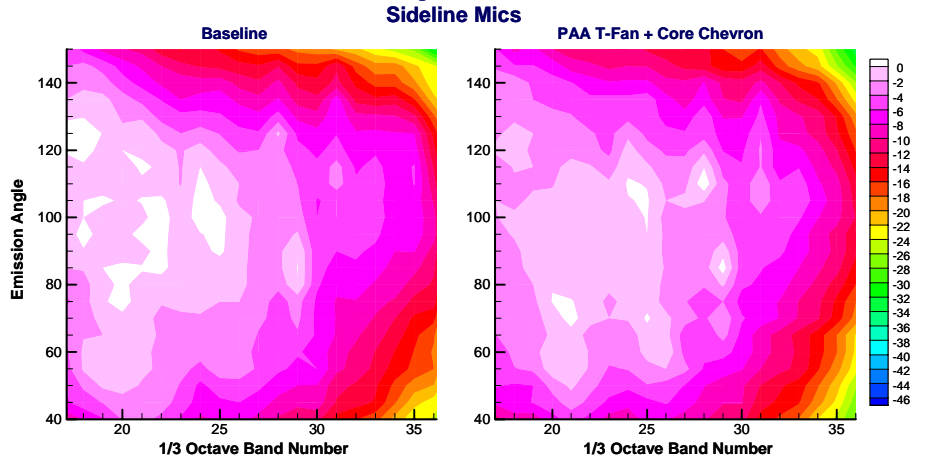

Figure 15. PAA T-Fan W/Core at Sideline - Cutback Power

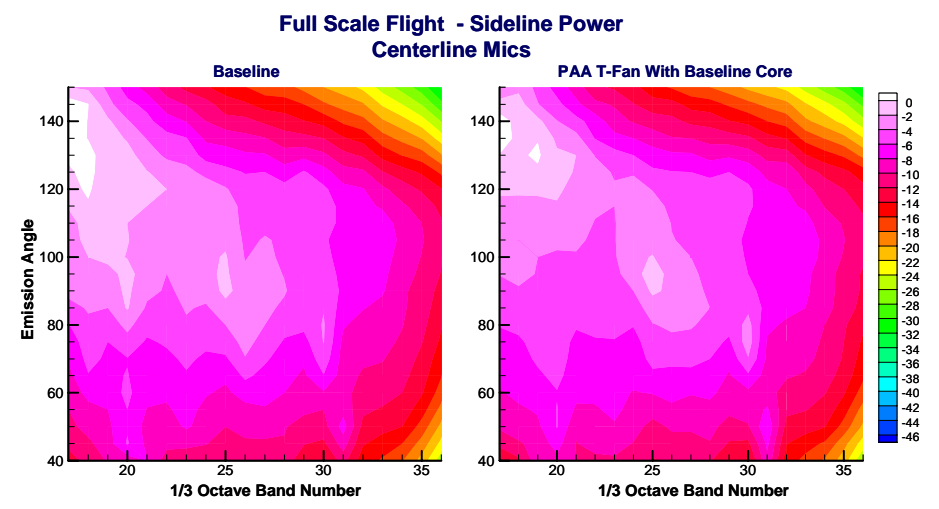

Figure 16. PAA T-Fan W/Baseline Core - Max Power 
time limitations the sideline azimuthal angle was not measured model scale no model scale data exists to compare. Finally, even with the scatter there appears to be significant noise reduction at sideline which is at least as great if not greater than the centerline microphones showed.

Figure 16 shows the spectral comparison for the PAA T-Fan chevron + baseline nozzle set for the sideline power setting from the centerline mics. This is the configuration pictured in Figure 1. There are two things to note about this comparison. First, the noise reduction is significantly smaller than the PAA T-Fan chevron with core chevron nozzle set and could be considered to be within the data repeatability. To understand if there is any noise reduction the power levels will need to be examined (See section IVB). Secondly, assuming the noise reduction seen in the comparison is real it seems most of the noise reduction is happening over angles forward of the peak jet noise region (from 100-120 degrees). Due to time and budget constraints there are no direct model scale results to compare to for this configuration although this is in line with model scale results shown by Mengle, Elkoby, et $\mathrm{al}^{10}$.

\section{B. Spectral Power Level comparisons}

As discussed earlier the power level comparisons shown have been corrected for differences in airplane speed. Due to space constraints and the need to match thrust only the max sideline (full) power setting levels will be shown in this section. This also allows for a more significant comparison to be made since at this power setting there are more repeats at a constant thrust. All the data are plotted and the lines through the data points are a linear average of the power levels of the available data. This allows for a comparison of the average and also the ability to assess the remaining data scatter.

Figure 17 shows the comparison of the aft arc power level (integrated from 90 to 145 degrees) of the PAA T-Fan + Core Chevron nozzle set. As shown there is significant noise reduction (up to $\sim 2 \mathrm{~dB}$ ) over the frequencies up to and including band 26. When compared to Figure 18 there does appear to be somewhat less peak jet noise reduction than the model scale results would predict but this is also in the region where the data scatter is greater. Around $150 \mathrm{~Hz}-200 \mathrm{~Hz}$ (band 20) where the full scale flight test data scatter is less the noise reduction matches very well with model scale data.

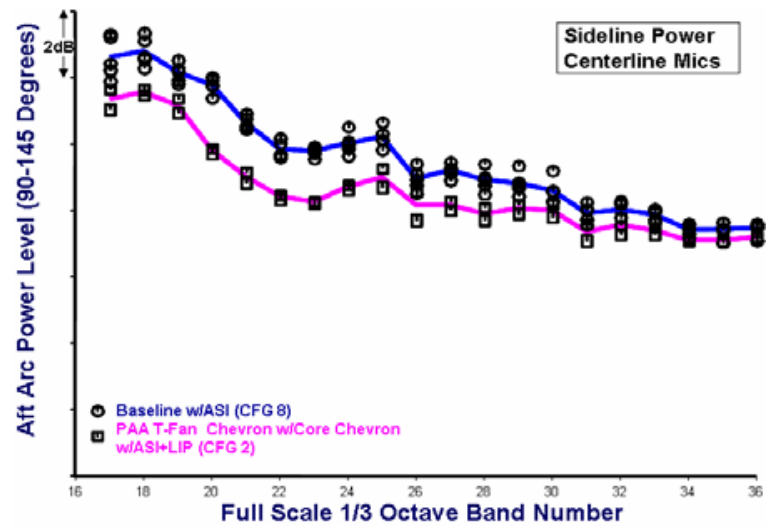

Figure 17. Full Scale Aft Arc Power Level

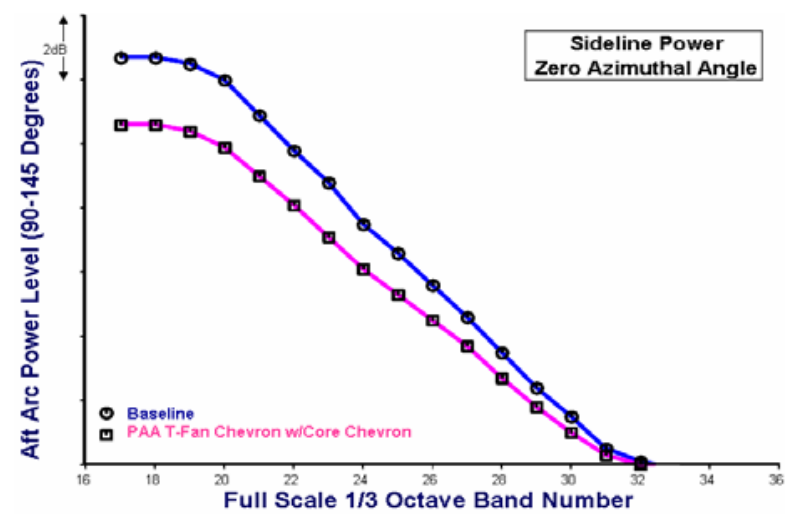

Figure 18. Model Scale Aft Arc Power Level

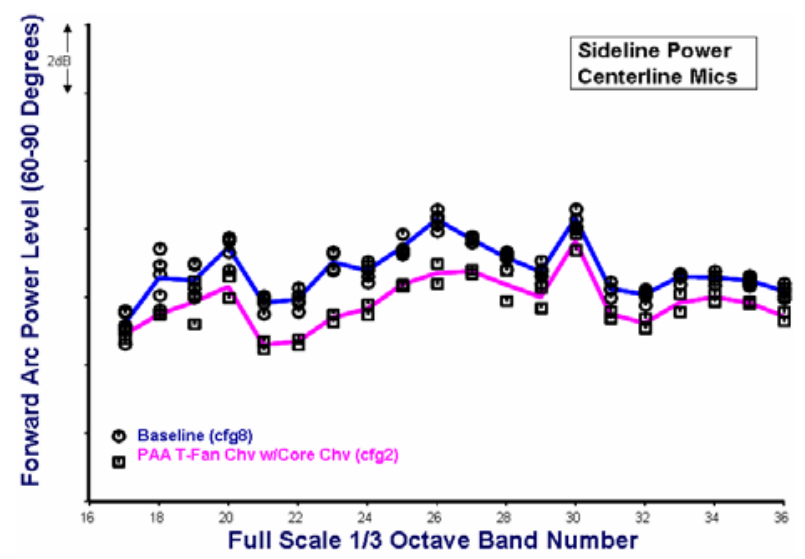

Figure 19. Full Scale Forward Arc Power Level

As pointed out earlier the model scale results differ significantly in the spectral shape from the flight test data. The reason for this is not known but could possibly be either an installation or another noise source not in the model scale data but still affected by the chevrons and free stream speed differences. 
Figures 19 and 20 show the comparison of the forward arc power level for the full scale and model scale results. Again the noise reduction over the low frequencies compare well. Also note the reduction in the high frequencies in the full scale flight test data. This reduction was not expected and could either be due to the inlet differences or data scatter. Looking at the model scale results in fact there is some evidence of a small increase on the forward arc high frequencies. The most significant thing to note is the similarity in the noise reduction across the low to mid frequencies.

Figures 21 shows the how the PAA T-Fan chevron + baseline nozzle set compares to the baseline set of nozzles on a aft arc power level basis. As shown even though the data scatter does overlap, on average there is a benefit for this configuration over the baseline nozzle.

This same result is shown in Figure 22 for the forward arc power level comparison. Note the presence of the fan tone at frequencies above the jet noise dominated region. Also note the absence of any detectable increase in the high frequency broadband that would normally be associated with a chevron nozzle.

\section{Model Scale Performance test results}

This section presents the results of the modelscale performance test conducted at ASE FluiDyne for each nozzle configuration. The results of this analysis will give the thrust values necessary to do plot the power level versus thrust in the next section.

The performance data shown are for velocity coefficients $\left(\mathrm{C}_{\mathrm{v}}\right)$ and effective areas $\left(\mathrm{A}_{\text {eff }}\right)$ calculated as follows. The velocity coefficient is calculated in the normal way:

$$
C_{v}=\frac{V_{\text {measured }}}{V_{\text {imix }}}
$$

where: $V_{\text {measured }}$ is the measured jet velocity calculated from the measured axial thrust and the total measured mass flow rate:

$$
V_{\text {measured }}=\frac{F_{\text {axial }}}{W_{\text {measured }}}
$$

where: $F_{\text {axial }}$ is the measured axial thrust and $W_{\text {measured }}$ is the total measured mass flow-rate of both streams summed together. The ideally mixed velocity is the mass flow-rate weighted velocity calculated as:

$$
V_{\text {imix }}=\frac{V_{I P} * W_{I P}+V_{I S} * W_{I S}}{W_{I S}+W_{I P}}
$$

where: $\mathrm{V}_{\text {IP }} \& \mathrm{~V}_{\mathrm{IS}}$ are the ideally expanded velocities of the primary and secondary streams, and $\mathrm{W}_{\mathrm{IP}} \&$

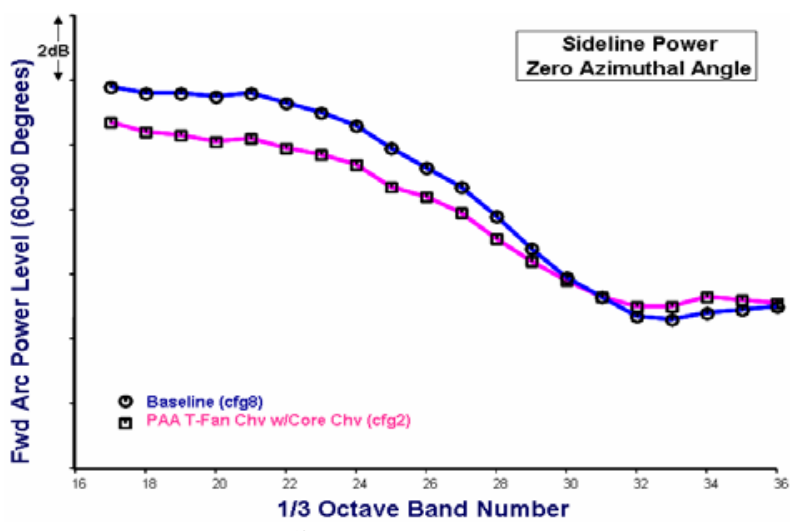

Figure 20. Model Scale Forward Arc Power Level

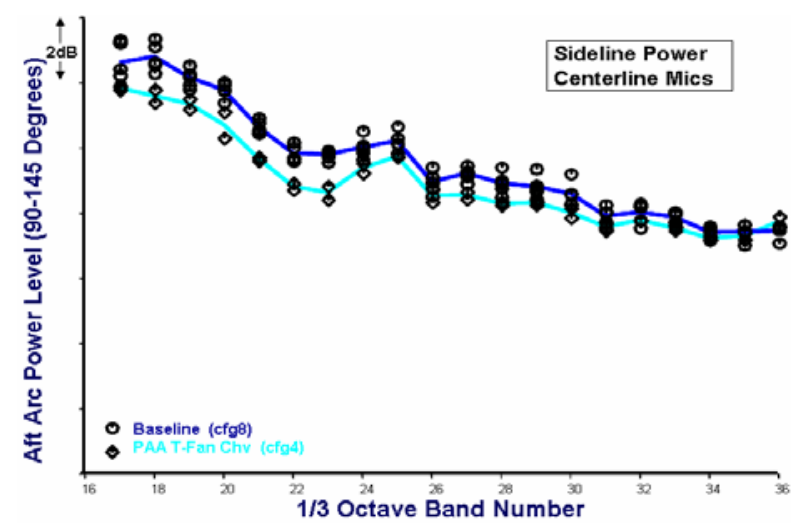

Figure 21. Full Scale Aft Arc Power Level

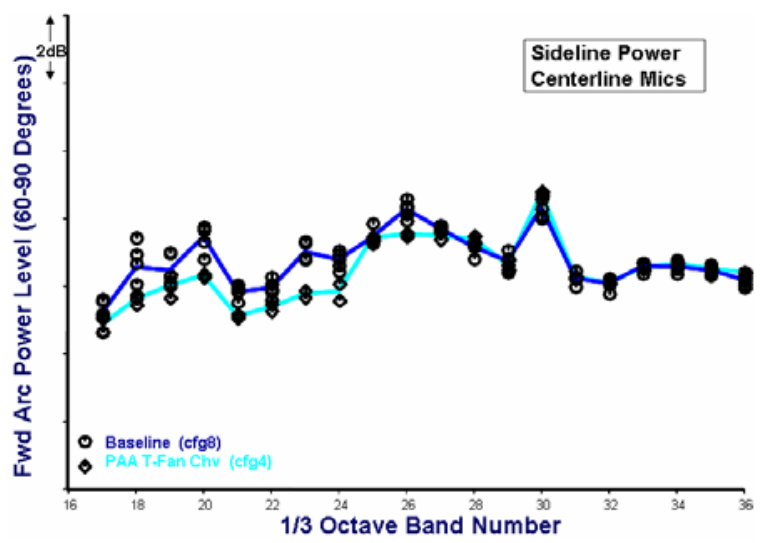

Figure 22. Full Scale Forward Arc Power Level

$\mathrm{W}_{\mathrm{IS}}$ are the ideal mass flow-rates of the primary and secondary streams. The effective area for each stream is calculated as follows: 


$$
A_{\text {eff }}=\frac{W_{\text {measured }}}{W_{\text {ideal }}} * A_{\text {geom }}
$$

where: $\mathrm{W}_{\text {ideal }}$ is the ideally expanded mass-flow rate of each stream $\left(\mathrm{W}_{\mathrm{IS}} \& \mathrm{~W}_{\mathrm{IP}}\right)$ and $\mathrm{A}_{\text {geom }}$ is the geometric reference area for the secondary nozzle or the primary nozzle.

Figure 23 shows a comparison of the velocity coefficient $\left(\mathrm{C}_{\mathrm{v}}\right)$ from the PAA T-Fan nozzle/core chevron nozzle set with the baseline set of nozzles as a function of secondary nozzle pressure ratio. As shown the PAA T-fan nozzle shows a slightly worse velocity coefficient over the takeoff power setting $(.14 \%)$ over the range of secondary nozzle pressure ratios from approximately 1.4 to 1.75. Potentially more important (from Specific Fuel Consumption (SFC) perspective) is a loss of $\mathrm{C}_{\mathrm{v}}$ at cruise which is seen to be less than $0.05 \%$ around $\mathrm{NPR}_{\mathrm{S}}$ of 2.30 .. However, as Figure 24 shows this loss at cruise is almost entirely if not completely coming from the core chevron nozzle. The important issue from a community noise stand point is whether the loss in velocity coefficient at the takeoff powers results in a loss of thrust at the takeoff conditions.

Figure 25 shows the comparison of the effective area for the PAA T-Fan to the baseline fan nozzle. As eq(6) shows the effective area $\left(A_{\text {eff }}\right)$ is a measure of how much mass flow-rate is being discharged by the nozzle. As shown, the PAA T-Fan nozzle passes significantly more mass flow-rate at the takeoff conditions. This effect is enough to completely offset the reduction in velocity coefficient at the takeoff powers and results in the PAA T-Fan nozzle having more thrust at a given fan RPM than the baseline nozzle. Figure 26 shows that this effect is quite significant and beneficial for configuration 2 with the PAA T-fan nozzle.

\section{Band Limited Overall Power Level comparisons}

To look at more than a select few set of power conditions and also to assure the comparisons are done at a constant thrust the band limited overall metric is used. These also allows a look at the low frequency aft arc which should be completely dominated by jet mixing noise and therefore have little or no contamination from other sources. Also since it is summing over both frequency and angle it results in a further reduction in data scatter. To understand if there is any significant forward arc high freq lift this section will present the band limited overall power levels summed over all the regions presented in section IIIc. Since this study is about jet noise the low frequency aft arc levels will be the majority of the comparisons shown.

Figure 27 shows the aft arc band limited overall power level for the PAA T-Fan + core chevron nozzle set for the centerline microphones integrated over the low frequency region. The data shown ranges from cutback power ( $\sim 60 \%$ thrust) through to full power ( $\sim 100 \%$ thrust). The plots now shows not only configuration 8 data (the baseline nozzle set with the same inlet except the lip is treated) but also now includes configuration 1 . This being a jet noise

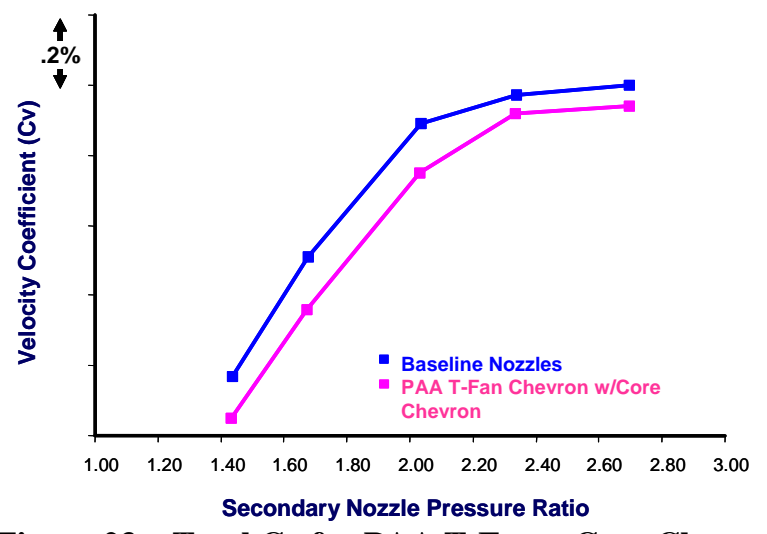

Figure 23. Total Cv for PAA T-Fan + Core Chevron

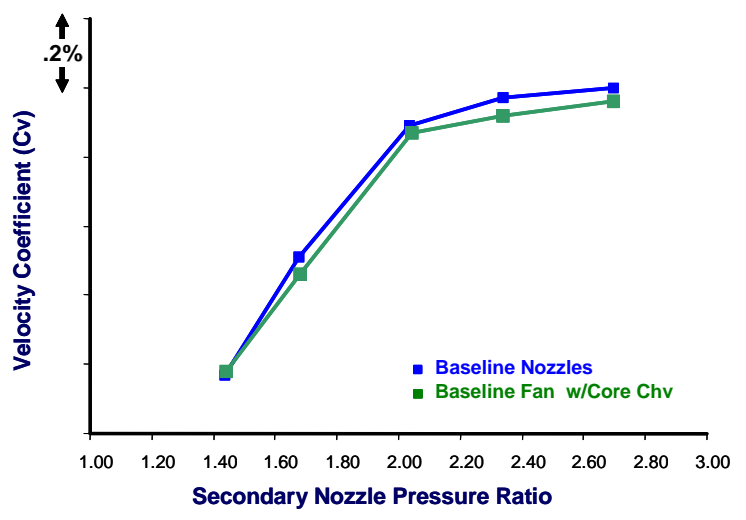

Figure 24. Total $\mathrm{C}_{\mathrm{v}}$ for Baseline fan with Core Chevron

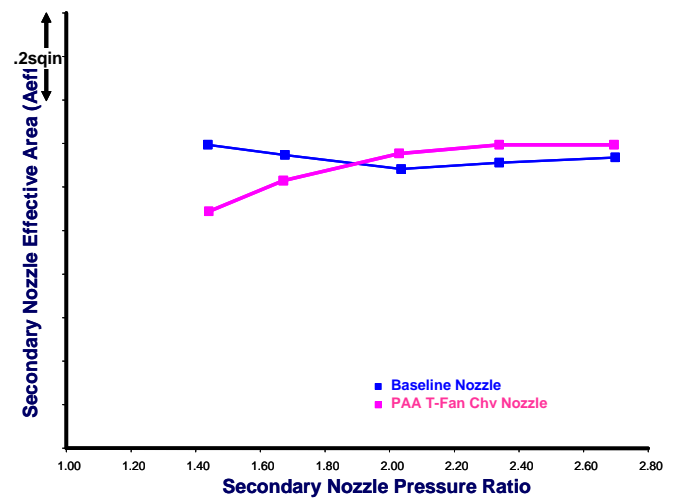

Figure 25. Effective Area of model scale PAA TFan Chevron nozzle. 
dominated metric the inlet differences should have no significant affect. Furthermore, the data is now shown as a function of thrust and thus removes any issues with data that have difference levels of thrust. As shown there is an almost constant reduction in the power level of $\sim 1.5 \mathrm{~dB}$ for in this jet noise dominated metric. As stated earlier this is a very significant noise reduction given the high BPR of the test engine.

Figure 28 shows the same comparison from the sideline microphones but now the PAA T-Fan Chevron plus baseline core nozzle set are also added. As expected the core nozzle chevrons increases the noise reduction of the fan nozzle and this increase is a function of power since as the power goes up the effective BPR drops (the core flow rate is a greater percentage of the total flow rate). This is true even though at this BPR most of the jet noise reduction comes from the secondary nozzle.

Figure 29 shows the band limited overall power levels for each region of integration for the three different nozzle sets tested. As shown even though there is significantly more data scatter at the high frequencies there is not evidence of any increase in the high frequency broadband.

\section{Conclusion}

This study validates with full scale flight test data that it is possible to obtain a small but still reasonable jet noise reduction in SPL of about $2 \mathrm{~dB}$ from azimuthally varying chevrons designed to incorporate PAA principles. This design also seems to allow for the SPL reduction in the aft-arc low frequencies without an increase in the forward-arc high frequency region typical of most conventional chevron designs. This has also been accomplished without a significant reduction in the thrust coefficient at cruise $(<0.05 \%)$ or a loss of thrust at takeoff. This type of chevron design therefore can be seen as an important tool for further jet noise reduction of high bypass ratio engines, particularly considering the ever more stringent noise requirements being implemented around airports.

\section{Acknowledgments}

The authors would like to thank the entire team from all the organizations that contributed to the dramatic success of the QTD2 flight test program. This includes the QTD2 partners Boeing, GE, Goodrich, NASA, and ANA. This especially includes all the on-site flight test, data processing and analysis teams. In addition if it were not for the dedicated team of engineers and mechanics at Boeing's Wichita facility (Now Spirit Aerospace) this hardware could not have been built and delivered on time to test.

\section{References}

${ }^{1}$ Herkes, W., Olsen, R., and Uellenberg, S., “The Quiet Technology Demonstrator Program: Flight Validation of Noise Reduction Concepts,” AIAA Paper No. 2006-2720, May, 2006.

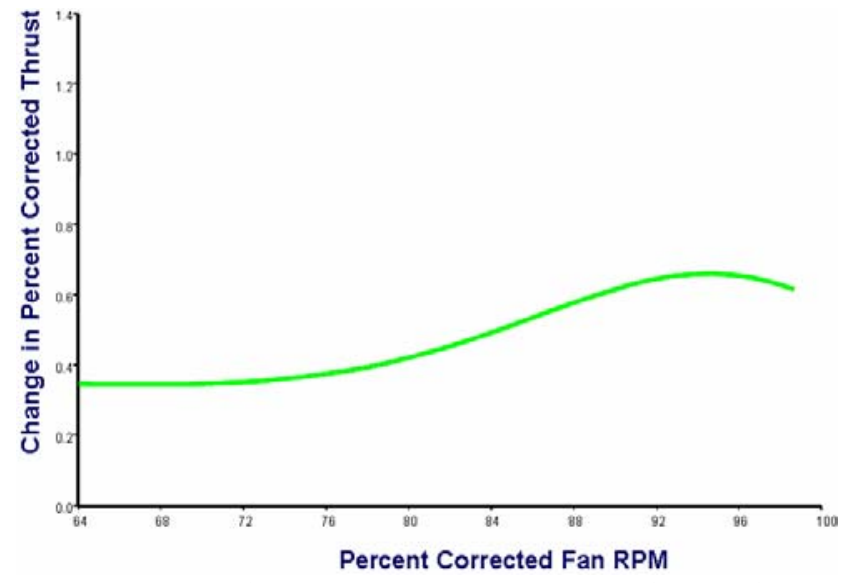

Figure 26. \% Change in corrected thrust for configuration 2 with the T-fan nozzle compared to the baseline nozzle.

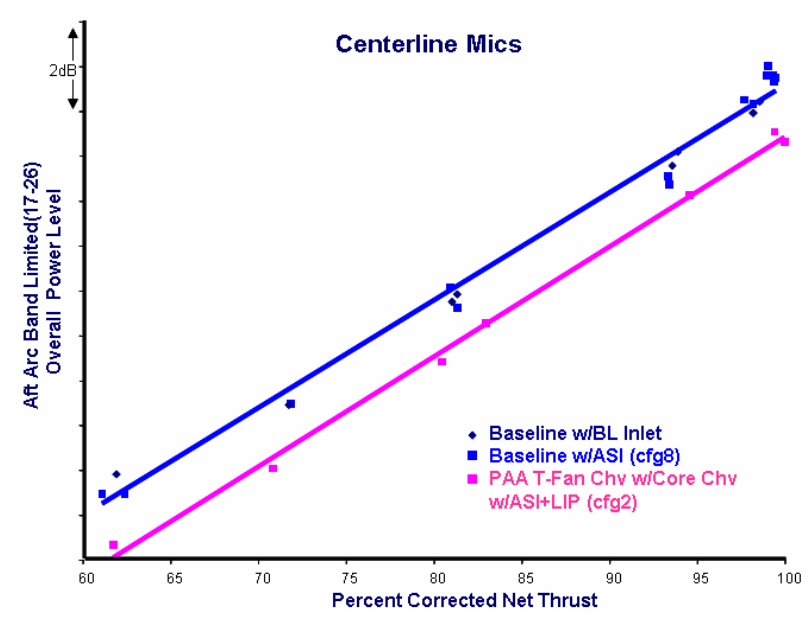

Figure 27. Band Limited Aft Arc Power Level Comparison

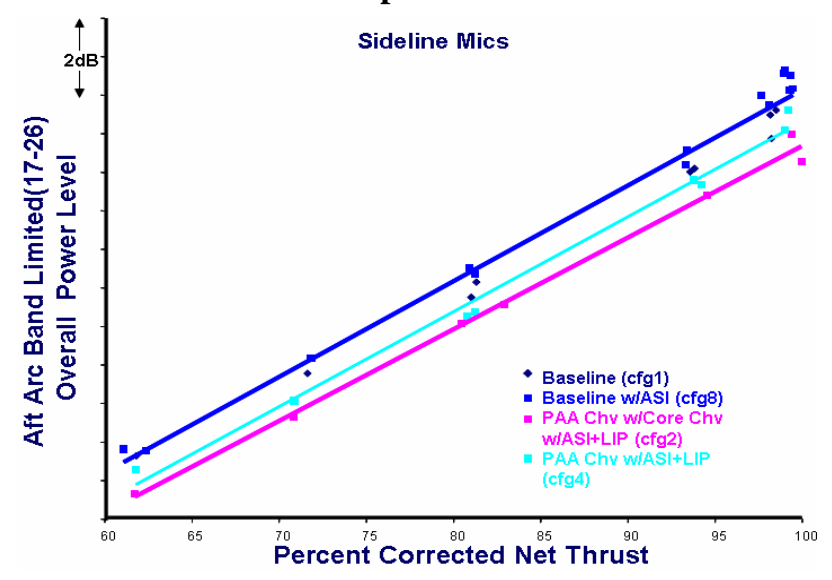

Figure 28. Band Limited Aft Arc Power Level - All Configurations compared

American Institute of Aeronautics and Astronautics 
${ }^{2}$ Janardan, B.A., Hoff, G.E., Barter, J.W., Martens, S., Gliebe, P.R., Mengle, V. and Dalton, W.N., “AST Critical Propulsion and Noise Reduction Technologies for Future Commercial Subsonic Engines, Separate-Flow Exhaust System Noise Reduction Concept Evaluation.” NASA CR-2000-210039, December, 2000.

${ }^{3}$ Martens, S., “Jet Noise Reduction Technology Development at GE Aircraft Engines.” ICAS Paper 842, presented at the International Council of the Aeronautical Sciences, Toronto, Canada, September, 2002.

${ }^{4}$ Nesbitt, E., Elkoby, R., Bhat, T., Strange, P., and Mead, C., "Correlating Model-Scale and Full Scale Test Results of Dual Flow Nozzles Jets,” AIAA Paper No. 2002-2487, June, 2002.

${ }^{5}$ Bhat. T.R.S., "Experimental Study of Acoustic Characteristics of Jets from Dual Flow Nozzles.” AIAA Paper 2001-2183, 2001.

${ }^{6}$ Massey, S., Thomas, R., Abdol-Hamid, K., and Elmiligui, A.: "Computational and Experimental Flow Field Analyses of Separate Flow Chevron Nozzles and Pylon Interaction.” AIAA Paper 2003-3212, 2003.

${ }^{7}$ Hunter. C., and Thomas, R., “Development of a Jet Noise Prediction Method for Installed Jet Configurations.” AIAA Paper 2003-3169, 2003.

${ }^{8}$ Thomas, R., and Kinzie, K., “Jet-Pylon Interaction of High Bypass Ratio Separate Flow Nozzle Configurations,” AIAA Paper No. 2004-2827, May, 2004.

${ }^{9}$ Elkoby, R., "Full-Scale Propulsion Airframe Aeroacoustics Investigation,” AIAA Paper No. 2005-2807, May, 2005.

${ }^{10}$ Mengle, V., Elkoby, R., Brusniak, L., and Thomas, R., "Reducing Propulsion Airframe Aeroacoustic Interactions with Uniquely Tailored Chevrons: 1. Isolated Nozzles,” AIAA Paper No. 2006-2467, May, 2006.

${ }^{11}$ Mengle, V., Elkoby, R., Brusniak, L., and Thomas, R., "Reducing Propulsion Airframe Aeroacoustic Interactions with Uniquely Tailored Chevrons: 2. Installed Nozzles,” AIAA Paper No. 2006-2434, May, 2006.

${ }^{12}$ Mengle, V., Elkoby, R., Brusniak, L., and Thomas, R., "Reducing Propulsion Airframe Aeroacoustic Interactions with Uniquely Tailored Chevrons: 3. Jet-Flap Interaction,” AIAA Paper No. 2006-2435, May, 2006.

${ }^{13}$ Massey, S., Elmiligui, A., Hunter, C., Thomas, R., Pao, S.P., and Mengle, V.G., "Computational Analysis of a Chevron Nozzle Uniquely Tailored for Propulsion Airframe Aeroacoustics” AIAA Paper 2006-2436, May, 2006.

${ }^{14}$ Mengle, V., Ganz, U., Nesbitt, E., Bultemeier, E., and Thomas, R., “Flight Test Results for Uniquely Tailored Propulsion Airframe Aeroacoustic Chevrons: Shockcell Noise,” AIAA Paper No. 2006-2439, May, 2006.

${ }^{15}$ Yu, J., Nesbitt, E., Chien, E., Uellenberg, S., Kwan, H., Premo, J., Ruiz, M., and Czech, M., “QTD2 (Quiet Technology Demonstrator 2) Intake Design and Validation,” AIAA Paper No. 2006-2458, May 2006.

${ }^{16}$ Czech, M., Uellenberg, S, Nesbitt, E., and Abdelhamid Y.,“A Novel On-site Tool for Flight Test Acoustic Data Processing,” AIAA Paper No. 2002-2502, June 2002.

\section{Centerline mics}

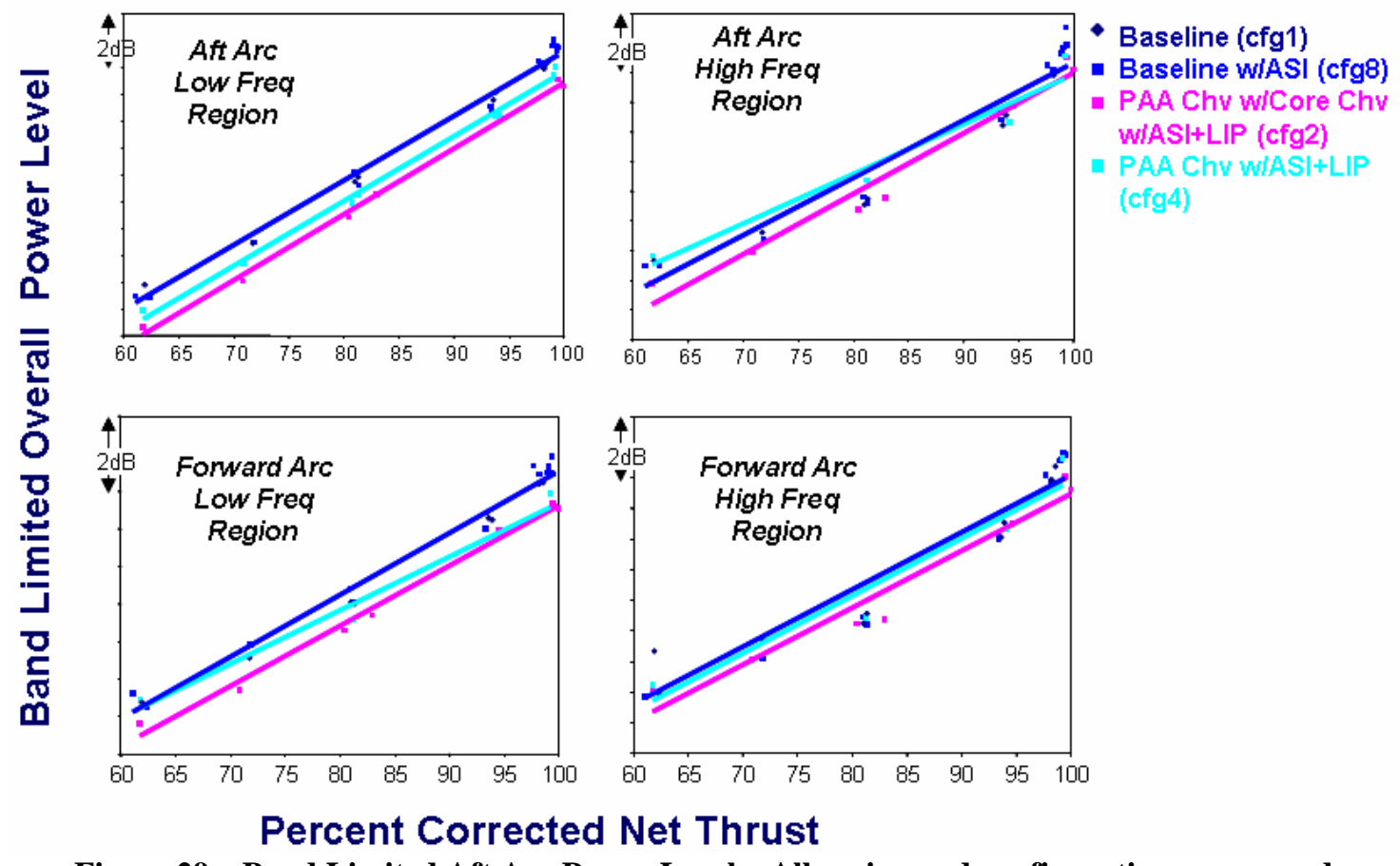

Figure 29. Band Limited Aft Arc Power Level - All region and configurations compared. 